Occultations of Stars by the Moon (visible at Greenwich)

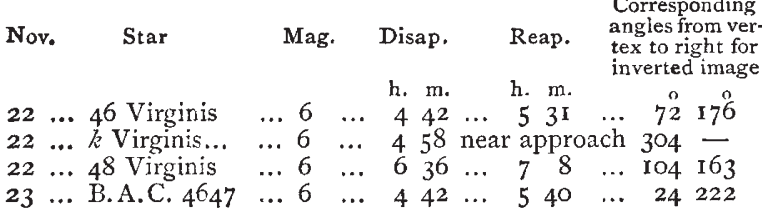

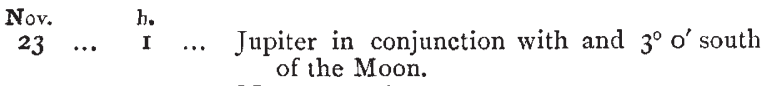

$23 \quad \ldots \quad$ I $4 \quad \ldots$ Mercury stationary.

Star

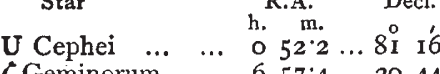

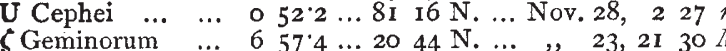

\begin{tabular}{llllllllllll}
\hline \\
S Canis Minoris ...
\end{tabular}

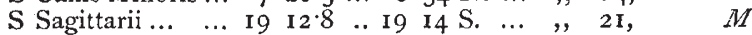

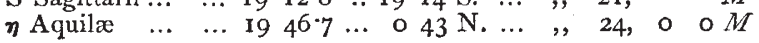
$M$ signifies maximum; $m$ minimum.

\section{Meteor Showers}

The Andromedes, maximum November 27, R. A. 24 ${ }^{\circ}$, Decl. $44^{\circ} \mathrm{N}$., form the most interesting shower of the week. A radiant near $\mu$ Persei, R.A. $60^{\circ}$, Decl. $49^{\circ}$ N., supplies very swift meteors; swift meteors are likewise seen from a radiant near $\eta$ Ursæ Majoris, R.A. $208^{\circ}$, Decl. $43^{\circ} \mathrm{N}$.

\section{GEOGRAPHICAL NOTES}

THE Bulletin of the Paris Geographical Society for the present year (Nos. I and 2) contain several papers of interest. We need do no more than mention M. Ch. Mannoir's annual report on the progress of geography during the past year, which fills 130 pages. M. Grandidier writes on the rivers and lagoons of part of the east coast of Madagascar, and M. Gouin, of Nam-dinh, contributes a long paper on Tonquin, which deals with the commercial geography of the country rather than with the geography proper. No. 2 opens with the report of a strong Committee of the Society on the orthography of geographical names, which will be read with interest. No elaborate or exhaustive reform are proposed; the suggestions are rather a series of simple moditications "based on good sense rather than on high philological science, which is only accessible to the few initiated." The Committee take up the programme of the Royal Geographical Society, "completing it in some respects, and making some additions sensible to musical ears." The bases of the proposals are the same as those of our own Society: (I) not to seek an absolute perfection in the representation of sounds; (2) to preserve in European names the form of the country of their origin ; (3) to retain in the case of other places the mode commonly employed. M. Rolland contributes a long paper on the hydrography and orography of the Algerian Sahara; and M. Marteil examines the map of the French establishments on the Senega recently issued by the Ministry of Marine. Lieut. Bauden describes a trip which he made last year along the Black River of Tonquin; and finally there is an account written by Dr. Potagos in 1880 of a journey which he made in the Pamir in 1870, including a visit to the famous Yakub Beg of Kashgar.

WE have received the Verhandlungen (Bd. xiii. No. 8) and the Zeitschrift (Bd. xxi. Nos. 4 and 5) of the Geographical Society of Berlin. The first contains only one paper, but that an interesting one, by Dr. Sievers, on a recent journey in the Sierra Nevada de Santa Marta, in Columbia. The object of the journey was to study the geology and physical gengraphy of the region, and especially to ascertain whether these mountains belong to the system of the Andes or not. As Dr. Sievers has only been back for a short time, he was unable to give any definite resuits, and he confines himself to describing the course of the journey, and to mentioning important points necessary for a proper understanding of the physical geography of the region. In the Zeitschrift, Herr Jung continues and concludes his analysis of the Indian census of 188I ; this is followed by a translation, from the Proceedings of the Russian Geographical Society, of Dr. Iwanow's paper on certain ancient monuments discovered by him in the course of a geological examination of Turkestan. Prof. Gelcich has a highly technical history of the methods of ascertaining the area of a country, and Dr. von Danckelmann one on the frequency of rain in the Indian Ocean. Herr Sandler makes a contribution to the history of cartography by giving an account of the life and works of johann Baptista Homann, a geographer of the latter "part of the seventeenth century. A curious map appended to this paper (which is of considerable length) shows, by means of white and red outlines, the world according to present cartography and according to Homann's maps. The number concludes with a short paper on the hot springs of Kamchatka.

IN a recent work on the geol gy and geography of Sumatra, M. Verbeek, a Dutch engineer, says that sixty-seven volcanoes are known to exist on that island. There may be more even than this, for parts of the north-west, which are covered with primæval forests, have never been penetrated. Two only of these are active, Merapi and Talang (or Soclau), the former being 2892 , and the latter 2542 metres in height.

THE October issue of the Bollettino of the Italian Geographical Society contains an account of an excursion made during the summer by E. Modigliani to the rarely visited island of Nias, which lies some thirty miles from the west coast of Sumatra, a little north of the equator. The explorer spent two months in the place, but owing to local feuds was unable to penetrate beyond Fadoro, a large village near Telok Dalam Bay on the south side. The natives, apparently of Malayan or Indonesian stock, but speaking a language quite different from Malay, and by Crawfurd described as " a simple, mild, and primitive people," he found on the contrary to be fierce and treacherous savages, everywhere addicted to head-hunting. Their hostility was such, that he failed to make any botanical or zoological collections; but fortunately secured eleven human skulls from the southern districts, which have been sent to the Anthropological Museum of Florence. No similar specimens appear to have hitherto reached Europe, nor are any found even in the Batavian collection. Head-hunting is taken so much as a matter of course, that on Sig. Modigliani offering to purchase some skulls, the rajah of Bavolovalani on the south coast quietly remarked that it would be rather an expensive business, as an expedition would have to be specially fitted out and sent to the hills to raid upon some neighbouring tribes and carry off the required number of heads. $\mathrm{He}$ had no idea of craniological specimens being collected except from the living subject. The interior of Nias still presents a promising field of exploration, never having been visited by any European travellers.

\section{LIGHTHOUSE ILLUMINANTS}

II.

\section{V.-Range of Lights in Hazy Weather}

THE observations on this subject of the Trinity House Committee have served to confirm the conclusions announced by M. Allard in his "Mémoire sur l'intensité et la portée des phares," 1876 , and in his more recent "Notes sur quelques objections relatives à l'emploi de la lumière électrique dans les phares." The Committee find that the gas and oil lights which are equal in clear weather are equal also in fogs; that in rather dense fog the more powerful light had but little advantage over the less powerful, for example, "the triform electric appearing at 1500 feet, while the quadriform gas and triform oil showed up together a little before the observers reached I 400 feet," and that the electric light, while suffering, according to the photometric results, a somewhat greater loss in hazy weather than the flame lights, is "visible at a greater distance than the highest powers tried in gas or oil." "Using M. Allard's formula, which appears to rest on well-established physical and physiological data, I have calculated the range in fogs of various degrees of thickness of some of the lights exhibited at the South Foreland. The range of a light, or the limit at which it is just lost or just picked up, is that limit at which its intensity is diminished by distance and haze to the minimum intensity perceptible by a good eye, such as the practised eyes of seamen are. M. Allard gives this minimum intensity, on the authority, of "des expériences qui ont été faites sur ce sujet au Champ de Mars," as that of I/100 Carcel at a distance of one kilometre on a perfectly clear night. This corresponds to $\frac{1}{3}$ candle at a distance of one nautical mile. When the air is not perfectly clear,

x Further Report of Mr. Vernon Harcourt to the Board of Trade on the Experimental Lights exhit ited at the South Foreland. Continued from p. 46 . 
its degree of transparency may be expressed by stating the fraction of light which escapes obstruction in passing through a certain length. Of this fraction the same fraction escapes obstruction in passing through another equal length of air, and so forth. Thus, if this fraction is called $a$, and $l$ is the intensity at any point of a beam of parallel rays, such as a beam of sunlight reflected from a plane mirror, after the beam has traversed a mile of hazy air its intensity is diminished to $l a$, at two miles its intensity is diminished to $l a^{2}$, and at a distance of $d$ miles to $l a^{d}$. But divergent light, such as is even the most condensed beam from a lighthouse, diminishes also as the square of the distance. Thus, if $L$ is a lighthouse light whose intensity at one mile is $L a$, its intensity at any number of miles, $d$, is $L \alpha^{d} \times \frac{1}{d^{2}}$, and when the combined effect of haze and distance is such that its intensity is only equal to that of $\frac{1}{3}$ candle at one mile, at that point the light ceases to be visible. Thus it is possible to calculate for any particular degree of haze what will be the range of any given light. To give some examples:- In a moderate uniform haze such that a single I08-jet gas-burner, showing as a fixed light of about 14,000 candles, was lost at a distance of $10^{\circ} 9$ miles, the same light shown in biform would be lost at I I .8 miles, while the corresponding triform and quadriform lights would be lost at 12.5 and 12.8 miles respectively. In a rather thicker haze, in which a single I08-jet gas-burner, showing as a revolving light of 60,000 candles, was visible up to 10 miles, but no further, the extreme range of the biform would be 10.73 miles, of the triform II' 16 miles, of the quadriform $1 x^{*} 48$ miles. In still thicker haze the increase of range obtained by increasing the power of the lighthouse light becornes not only absolutely but relatively less,

Light shown

\begin{tabular}{lllllllll}
\multicolumn{1}{c}{ Light shown } & \multicolumn{4}{c}{ Range in Nautical Miles } \\
Single I08-jet, M. I. lens & $\ldots$ & 2 & $\ldots$ & I & $\ldots$ & 0.5 \\
Biform ", &, & $\ldots$ & $2 \cdot 1 \mathrm{I}$ & $\ldots$ & I.05 & $\ldots$ & 0.52 \\
Triform &, &, & $\ldots$ & $2 \cdot 17$ & $\ldots$ & I.08 & $\ldots$ & 0.54 \\
Quadriform &, &, & $\ldots$ & $2 \cdot 22$ & $\ldots$ & I. I & $\ldots$ & 0.55
\end{tabular}

The above results represent the maximum range of the direct beam through uniform haze of lights of the same kind but varying in power. But in certain cases the increase of range gained by increasing the power of the light may be either less or greater than it is in the foregoing case.

In the first place, the light which has suffered obstruction is diverted from its direct course but is not lost ; and a portion of this light may reach the eye from a direction slightly different from that of the source of light, producing the impression of a halo or burr. Prof. Stokes, Pres. R.S., who has kindly given me much help in considering this subject, concludes that, especially in a fog in which the particles of water are not very minute, the burr might be seen at a substantially greater distance than that at which the direct light could be seen. "The intensity of this diffused light will not decrease in geometric progression as the distance from the source increases, but rather will tend ultimately to decrease inversely as the square of the distance ; but being so widely spread, there will be danger of its being unperceived unless it be flashy." In this case the more powerful lights would retain in fog more nearly the advantage which they possess in clear weather, in which a fourfold light has double the range of a single light. But since the eye can distinguish between the point of light which is seen by the direct rays and the blurred nimbus, whose properties Prof. Stokes has investigated, the question whether the range of powerful lights is materially increased by the diverted and re-diverted light which surrounds the principal beam could be solved by an appeal to experience.

In answer to my inquiry whether it often happens that in approaching a lighthouse on a hazy night that which is first seen is an indistinct brightness or halo, not the light itself, and whether this effect is seen at considerable distances or only at short distances, and in what kind of fog, the Deputy Master of the Trinity House tells me that it happens, occasionally, at short ranges, in thick fog or mist, when nothing of the light is seen beyond I or 2 miles. "In clearer weather (i.e., slight haze) this peculiarity is not observable at any range; it is the direct beam from the lantern (of course lessened and indistinct by reason of the density of the atmosphere) which then comes to the eye of the observer when approaching from seaward." I think, therefore, it may be concluded that at short distances powerful lights may occasionally have an advantage over feebler lights greater than is indicated by M. Allard's formula, in consequence of the scattered light being less diminished by fog than the direct light.

There are two other cases in which the formula is not immediately applicable; the second exception being, if the haze is not uniform. This case may be illustrated by taking an extreme example. Suppose that the amount of fog extending 5 miles from a lighthouse were just sufficient to extinguish a light of 60,000 candles, and that beyond this distance the air were perfectly clear, a light of four times the initial power would have at the margin of the fog four times the minimum visible brightness, and would only disappear altogether at a distance of ro miles. But, on the other hand, if the fog were thicker further to seaward, the larger light would have scarcely any advantage over the smaller light.

Thirdly, if the lights compared differ in quality, of which the visible sign is colour, as well as in power. In this case the particles of water of which haze at sea consists (differing from the coloured particles of a London fog) are only likely to exercise a selective action on lights of different refrangibilities when the particles are so small as to be comparable with a wave of light. In a thick mist, in which the particles of water have often a visible magnitude, this effect is probably absent. Clouds are of this character, and sunlight is not reddened by passing through them. But the red colour of the sun when near the horizon, and the assimilation in colour of the electric light to gas-light when seen from a distance through slight atmospheric haze, shows that such haze does interfere with the more refrangible blue rays, to a greater extent than it does with the yellow, orange, and red rays. It is therefore certain that the electric light, which contains a relatively large proportion of the more refrangible rays, suffers a greater loss than the light from gas or oil flames in certain states of the atmosphere. The larger particles of mist or rain probably obstruct light of all sorts in the same degree. If we suppose that the effect of haze is to cut off all the blue and violet rays, the loss to the flame lights would not exceed I or 2 per cent., while that of the electric light, which is perhaps rather bluer than sunlight, may amount to 20 per cent. But this loss, though considerable, would not materially affect the range of the electric light in hazy weather. ${ }^{\text {I }}$

It has been claimed as an advantage of multiform lights, compared with the electric arc behind a small lens, that the larger surface of illuminated lens is more favourable to visibility in hazy weather; and the late Sir W. Siemens gave some countenance to this view. Speaking in the discussion of Sir James Douglass's paper "On the electric light applied to lighthouse illumination," I879, he said:- "He had held that, in order to get more penetrating power, not intensity alone, but intensity with quantity as represented by large surface, would be required." M. Allard in his "Note," pp. Io and II, makes some interesting observations on this subject, but deals rather with visibility at great distances in clear weather than with visibility through haze. I do not know on what grounds, either of theory or observation, the opinion formed by Sir W. Siemens is based. Desiring further information on this and some other points, I have consulted Lord Rayleigh, Sec. R.S., who with Prof. Stokes joined me in a visit to the South Foreland lights a year ago. I may quote his opinion :- "With the same total brightness of source, and angle of divergence, it can make no difference at a distance (at which the apparent magnitude of the lens is inappreciable), whether the lens be large or small. At smaller distances the advantage might be with the smaller lens. So far as I see, the only advantage that the large lens could ever have would be more room for a bulky light, which, with a small lens, might give too great a divergence."

While referring to the assistance I have received from Prof. Stokes and Lord Rayleigh, to whom I desire to accord my thanks, I should mention that I have received from both the same emphatic suggestion, that further trial should be made of sudden flashes in fog. Lord Rayleigh writes: "I should like to see proper experiments tried on sudden and periodic flashes, such as might be produced by gunpowder, the periodicity serving for identification and the intermittence being necessary to

I Since this report was written, a paper has been communicated to the Royai Society by Captain Abney, R.E., F.R.S., and Major-General Festing, R.E., F.R.S., giving the result of measurements of the illuminating power of different parts of the spectrum of the electric arc. According to these measurements, the illuminating power of that part of the light from the electric arc which lies beyond the line " $\mathrm{E}$ " in the spectrum, including the greater part of the green rays as well as the blue and violet rays, is rather less than one-sixth of the total illuminating power. 
get the necessary contrast, which is here between appearances at consecutive times, instead of as in ordinary vision between appearances in neighbouring directions."

Prof. Stokes writes, on various occasions:-"The diffused light of a powerful lamp would be weak and perfectly steady, and might thus escape notice, while a diffused light, even though no stronger, if almost momentary like lightning might be sufficient to attract attention, and you could afford to throw great chemical force into the formation of a flash which was to last only, as it were, for a moment." "If there are to be any more experiments, I think it would be well worth while to try explosions." "The more I think of it the more disposed I am to think that it would be worth while to try some experiments with flashes, I mean with explosions. The plant would not be at all costly ; in fact, it would hardly cost anything. The chemicals would not cost very much. Preliminary experiments on a small scale, which could be tried anywhere, would show what chemicals were good to use in order to get a flash as bright as may conveniently be. But when the actual experiments in fog are tried, the quantity used should not be by any means very small. It should be enough to make the quantity of light for the moment much greater than what was kept up in your most powerful burners; but that would not require a very large quantity."

I should add that Prof. Stokes is aware that "flares" have been tried and used, but is clearly of opinion that further trials should be made in that direction. As to the great effect of sudden illumination in attracting attention there can be no doubt; but I find it hard to believe that in a fog in which an observer at a small distance was unconscious when the beam from the electric arc, through such a lens as the Mew Island lenses, passed quickly across him, any "flare" would be perceptible at the same distance. I do not know whether the experiment has been tried of combining a light-and-sound signal, by placing the materials used to produce a flash together with a charge of compressed gun-cotton in the head of a rocket, and so firing the rocket that it would explode at a fixed distance and bearing from the station and at a moderate altitude. A rocket will go through any fog, and might be used to give a lift seaward to the light and sound.

\section{VI.-Cost of each System}

I have not the data which are necessary for forming an independent opinion upon the estimates furnished in the Trinity House report. These estimates rest on unexceptionable authority; and I only venture to make any remarks on the subject because I am not entirely satisfied with the position assigned to the electric light.

I gather from the reference to the photometric results of Mr. Valentin that in a former estimate the cost was considered in relation to the yield of light by each illuminant. And I think that an estimate of what light can be had on any system for a given expenditure, or what the cost is on any system of a desired quantity of light, is needed to make the comparison of the relative cost complete. For example, a comparison is made in the Report (Tables I. and II., pp. 62-63), between a "first order oil-lighted tower for one six-wick burner only," and a "gas station to show a quadriform light of four times 68 -jet power." The annual cost of maintenance, including interest on capital outlay, is estimated at $724 l$. for the first, and $1687 l$. for the second. But the light from a six-wick burner shown as a fixed light is probably rather less than 7000 candles, while that from the 68 -jet quadriform is 35,000 candles. Thus, if such a quadriform were substituted for or adopted instead of the single light, both the cost and the light would be largely increased, but the increase of light would be more than double the increase of cost. Comparing the two as revolving lights, the increase of light would be one-third greater than the increase of cost. So in the comparison between the cost of the electric light and the other illuminants. The expense of annual maintenance, with interest on capital outlay, is estimated as being one-seventh greater for the electric light than for the quadriform 68-jet gas; but if the yield of light is taken into account, the figures appear very differently. The electric light is ten times as powerful as the quadriform. The actual cost of light, which is the commodity produced, may be compared in the two cases by stating the cost of maintaining for one year each 1000 candles intensity of light in the beam sent forth. By the electric arc the cost is about Il., by the quadriform gas $8 \%$. IOs.

As to the actual estimate of the cost of the electric light, I venture to suggest that some reduction may be found practicable. Two engines of 30 horse-power, at a cost of $1250 l$, seems a very full provision for the unfailing maintenance of one arc light. The actual horse-power absorbed by one of the De Méritens machines is given by Prof. Adams as $10^{\circ} 4$. M. Allard state; the price of one of $\mathbf{M}$. de Méritens' machines, tested and recommended by him in 1880 , as $350 \%$. Dynamo-machines are, I believe, less costly. I think all that is needful and best of machines, lamps, and cables, may now be obtainable for less th in $2154 \%$; and the estimate of $1217 l$. a year for wages, clothing, coke, oil, carbons, \&c., and repairs and renewals, may perhaps be found in excess of the necessary cost. M. Allard gives the following details of the cost of the apparatus and expenses at Grisnez :-

Two steam-engines of from five to six horse-power ... $\quad \underset{488}{f}$

$\begin{array}{lllllll}\text { Two magneto-electric machines } & \ldots & \ldots & \ldots & \ldots & \ldots & 852\end{array}$

$\begin{array}{lllllllllll}\text { Four lamps } & \ldots & \ldots & \ldots & \ldots & \ldots & \ldots & \ldots & \ldots & \ldots & 240\end{array}$

$$
\begin{aligned}
& \begin{array}{lllllll}
\text { Total } & . . & \ldots & \ldots & \ldots & \ldots & \mathbf{1} 580
\end{array} \\
& \begin{array}{llllllllll}
\text { Annual expenses } & \ldots & \ldots & \ldots & \ldots & \ldots & \ldots & \ldots & \ldots & 537
\end{array}
\end{aligned}
$$

He also furnishes an estimate, which I transcribe, of the average cost of converting an oil lighthouse into an electric lighthouse :-

Engine-house, keepers' dwellings, water-supply, \&c. ... $\underset{1600}{\mathscr{6}}$

Two steam engines, of from six to eight horse-power,

$\begin{array}{llllllll}\text { with shafting and straps } & \ldots & \ldots & \ldots & \ldots & \ldots & \ldots & 640\end{array}$

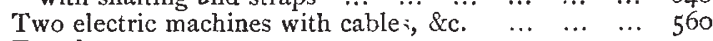

$\begin{array}{lllllllllll}\text { Four lamps } & \ldots & \ldots & \ldots & \ldots & \ldots & \ldots & \ldots & \ldots & \ldots & \mathbf{2 4 0}\end{array}$

First order lantern with oblique framing $\quad \ldots \quad \ldots \quad \ldots \quad 800$

Optical apparatus, two feet in diameter, with arrange-

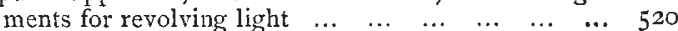

Sundries, packing, carriage, and setting up $\quad \ldots \quad$... 240

$\begin{array}{llllllllll}\text { Contingencies } \ldots & \ldots & \ldots & \ldots & \ldots & \ldots & \ldots & \ldots & \ldots & 400\end{array}$

$\begin{array}{lllllll}\text { Total } & \ldots & \ldots & \ldots & \ldots & \ldots & 5000\end{array}$

Add "First cost of an ordinary first order oil-lighted tower" (T. H. Report, Part 1., p. 75), less "Apparatus, lantern and glass," viz. $4834 l$. ; and it would seem to follow that the first cost of an electric light station need not exceed ro, oool.

The rather large difference between this estimate and that of I 7,749l. furnished by the Trinity House Conmmittee has no doubt already received the consideration of the Elder Brethren, who have had the details of M. Allard's scheme before them.

In order to obtain some further information, I have inquired of a London firm of electric light contractors as to the cost of such an installation, and have received the following figures :-

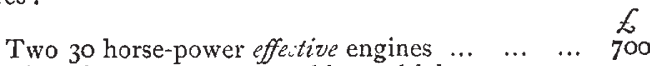

Three lamps, necessary cable, and labour $\ldots . .6$.

Two dynamos and spare armature to fit either $\ldots . .480$

It will be seen that these figures are not very different from those of M. Allard's estimate.

In concluding this report I desire to thank the Elder Brethren of the Trinity House, and especially the Members of the Committee, for the kindness which has made the duty of co-operating with them in this inquiry a continual pleasure.

March 9, I886

A. VERNoN HARCOURT

Letter to the Board of Trade from the Commissioners of Northern Lighthouses

Northern Lighthouse Board, 84, George Street, Edinburgh, December 10, I885

SiR, - I am directed by the Commissioners of Northern Lighthouses to acknowledge the receipt of your letter of the 3rd instant, in which you request to know whether the Commissioners propose to make any general report or observations relative to the recent Lighthouse Illuminants Experiments at the South Foreland.

In reply I am directed to state that in view of the very able and exhaustive Report (Part I.) by the Committee of the Elder Brethren on this subject, in the conclusions of which the Commissioners concur, and of the report by their engineers dated October I4 last, which accompanied my letter to the Elder Brethren of the following day, and copy of which is herewith transmitted for the information of the Board of Trade, the 
Commissioners do not propose, at least in the meantime, to make any general report or further observations in regard to these experiments. - I am, \&c.,

(Signed) J. M.
The Assistant Secretary, Harbour Department, Board of Trade

Report on Part I. of Report by the Specixl Committee of the Elder Brethren on Lighthouse Illuminants, by T. and $D$. Stevenson, Engineers, to the Northern Lighthouse Board

On September 2 last, the Board remitted to us, for consideration and report, Part I. of the Report of the Committee of the Trinity House, on the experiments at South Foreland, and having perused the reports of the experiments, we now beg to report as follows :-

As the Board is aware, the object of these experiments was to determine the relative merits of gas, oil, and electricity, as lighthouse illuminants, especially as regards their penetrative power in fog; also to ascertain the merits of certain optical arrangements, and test certain improved oil and gas burners patented by Sir James Douglass and Mr. Wigham. We think that these experiments embrace all the suggestions that were brought under the notice of the Elder Brethren for trial by the Board of Trade, and which led that Board to suggest that this train of experiments should be entered upon.

We have had several opportunities of inspecting the various kinds of apparatus, and also of witnessing the experiments, and in our opinion these experiments have been of an exhaustive character, and have been conducted with great care, and, we believe, in a spirit of the most perfect fairness and impartiality to all parties; and we have further to express our concurrence in the conclusions of the Cominittee as expressed in the following terms :-

"(I) That the electric light, as exhibited in the A experimental tower at South Foreland, has proved to be the most powerful light under all conditions of weather, and to have the greatest penetrative power in fog.

"(2) That for all practical purposes the gaslight, as exemplified by Mr. Wigham's multiform system in B experimental tower, and the oil light, as exemplified by the Trinity House Douglass six-wick burners in multiform arrangement up to triform in $\mathrm{C}$ experimental tower, when shown through revolving lenses, are equal, light for light, in all conditions of weather; but that quadriform gas is a little better than triform oil.

"(3) That when shown through fixed lenses, as arranged in the experimental towers, the superiority of the superposed gas light is unquestionable. 'The larger diameter of the gas flames and the lights being much nearer to each other in the gas lantern, give the beam a more compact and intense appearance than that issuing from the more widely separated oil burners.

"(4) That for lighthouse illumination with gas, the Douglass patent gas-burners are much more efficient and economical than the Wigham gas-burners.

"(5) That for the ordinary necessities of lighthouse illumination, mineral oil is the most suitable and economical illuminant, and that for salient headlands, important landfalls, and places where a very powerful light is required, electricity offers the greatest advantages."

We may explain that so far back as 1869 we had also occasion to conduct a series of experiments at Edinburgh on certain large burners patented by Mr. Wigham, and brought before the Board, with the view of increasing the power of sea lights, and again in 1870 a further series of experiments was carried out by us, by the direction of the Board of Trade, on the merits of the electric light, and certain important results were obtained during these sets of experiments at Edinburgh. The general result of the gas experiments then made was that the large 52 -jet gasburner was in no way superior to the 4-wick oil-burners when used in connection with the ordinary annular lens, as the "greater portion of the 7-inch gas flame" was with that size of lens necessarily ex-focal. The large burner was slightly superior, however, when used in a fixed light apparatus. Our opinion, which has been corroborated by the recent experiments, therefore, was that in order to bring out the full power of these large flames, an apparatus of larger focal distance than usual must be employed, and hence we designed the lens of $1,330^{\mathrm{mm}}$ radius, which has recently been tried at the South Foreland with the most satisfactory results.

The electric light experiments made at Edinburgh in $1867-$ $\mathbf{1 8 6 9}$, showed that if the electric light beam was made to diverge artificially to the same extent as the 4-wick oil flame, it was in no way superior in brilliancy, and pointed to the advisability of adopting for the electric light the azimuthal condensing system of Mr. Thomas Stevenson. This system has been adopted for the electric light apparatus at the South Foreland experiments. The Edinburgh experiments further showed that it was necessary in any test of the intrinsic merits of electricity, gas, or vil, that the maximum condensation consistent with the requirements of navigation for each should be employed. At the South Foreland experiments, however, the condensation of the electric light was only $30^{\circ}$ into $5^{\circ}$, that is only 6 times, whereas the Isle of May apparatus, which was exhibited at the South Foreland, conclensed $45^{\circ}$ into $3^{\circ}$, that is I 5 times. Had this or a still more condensed light been used in the experiments, the electric light would have shown even greater superiority than it did.

We shall afterwards report as to what, in our opinion, is the arrangement of optical apparatus best suited for each illuminant. $\quad$ (Signed) $T$. and D. STEVENSoN

Edinburgh, October 14, I 885

\section{OFFICIAL REPORT ON THE USE OF OIL AT SEA FOR MODIFYING THE EFFECT OF BREAKING WAVES ${ }^{1}$}

THE following Memorandum, dated June 16 last, on the use of oil at sea for modifying the effect of breaking waves, has recently been printed and circulated by the Admiralty :-

"Many further practical experiments at sea have been made since the report by Capt. Chetwynd, R.N., to the Royal National Lifeboat Institution, dated September 30, 1884, on the use of oil for smoothing broken or troubled waters, which report was communicated to Commanders-in-Chief in Admiralty Circular Letter of December I, I884, N.S. $\frac{3206}{8305}$

"As these further experiences go to show that the use of oil, under different circumstances, is of very extended and simple application, my Lords Commissioners of the Admiralty consider it desirable, in order that the facts may be generally known, to re-issue the report above mentioned, together with such other information as may serve for the guidance of officers, whose attention is hereby called to the fact that a very small quantity of oil skilfully applied may prevent much damage both to ships (especially the smaller classes) and to boats by modifying the action of breaking seas.

"The principal facts as to the use of oil are as follow :-

"On free waves, i.e. waves in deep water, the effect is greatest.

"In a surf, or waves breaking on a bar, where a mass of liquid is in actual motion in shallow water, the effect of the oil is uncertain, as nothing can prevent the larger waves from breaking under such circumstances; but even here it is of some service.

"The heaviest and thickest oils are the most effectual: refined kerosene is of little use ; crude petroleum is serviceable when nothing else is obtainable; but all animal and vegetable oils, such as waste oil from the engines, have great effect.

"A small quantity of oil suffices, if applied in such a manuer as to spread to windward.

"It is useful in a ship or boat, both when running, or lying-to, or in wearing.

"No experiences are related of its use when hoisting a boat up in a seaway at sea, but it is highly probable that much time and injury to the boat would be saved by its application on such occasions.

"In cold water, the oil being thickened by the lower temperature, and not being able to spread freely, will have its effect much reduced. This will vary with the description of oil used.

"The best method of application in a ship at sea appears to be hanging over the side, in such a manner as to be in the water, small canvas bags capable of holding from one to two gallons of oil, such bags being pricked with a sail needle to facilitate leakage of the oil.

"The position of these bags should vary with the circumstances. Running before the wind, they should be hung on + From the Board of Trade Journal. 